\title{
Knowledge Creation in Constructivist Learning
}

\author{
Sajna Jaleel $^{1, *}$, Alie Molly Verghis ${ }^{2}$ \\ ${ }^{1}$ School of pedagogical Sciences, Mahatma Gandhi University, India \\ ${ }^{2}$ Faculty Improvement Programme, School of pedagogical Sciences, Mahatma Gandhi University, India
}

Copyright (C) 2015 Horizon Research Publishing All rights reserved.

\begin{abstract}
In today's competitive global economy characterized by knowledge acquisition, the concept of knowledge management has become increasingly prevalent in academic and business practices. Knowledge creation is an important factor and remains a source of competitive advantage over knowledge management. Constructivism holds that learners learn actively and construct new knowledge based on their prior knowledge. Therefore, there needs to be a shift in locus of constructing knowledge from the individual to collective construction. The concept of knowledge building communities has emerged recently as a foundation for re-examining pedagogical approaches in education. To understand the true nature of knowledge, it is necessary to recognize that tacit and explicit knowledge are essential to knowledge creation. Knowledge can be created through conversion between tacit and explicit knowledge by four different modes. The four modes of knowledge conversion are created when tacit and explicit knowledge interacts with each other. It is in this very act of conversion from tacit to explicit knowledge that learning is created. Educators must understand the dynamic nature of knowledge itself in order to practice effective knowledge management in multi-disciplinary contexts. It is also crucial for educators to focus on effective methods of delivering content, the media used, and the overall quality of the instruction materials. Information technology facilitates knowledge management practices by disseminating knowledge and making codified knowledge retrievable. The study therefore tries to find out the effectiveness of e- learning in developing the knowledge creation ability of student in the four modes suggested by Nonaka and Takeuchi .
\end{abstract}

Keywords Knowledge Creation, Tacit and Explicit Knowledge, Socialisation, Externalization, Internalization, Combination, E-learning

\section{Introduction}

Contemporary knowledge society attaches much importance to the concept of knowledge management. Views of learning are strongly focused on ideas of student-centeredness and social contexts for learning where learning occurs as a socio-cultural system, within which learners interact and receive scaffolding through the help of others. These ideas are grounded in socio-cultural theories of learning of Vygotsky [1] and more recently in communities of practice theories. According to communities of practice theories, 'learning is an inherently social and participatory activity, conversational in nature, and where participation involves mutual engagement with other members of the group in negotiating meaning.'[2] Choy et al. have stated that 'A community can provide the social interactions and relationships which are essential for learners to collaboratively construct shared knowledge.'[3]

Scardamalia et.al [4] suggest that 'there needs to be a shift in locus of constructing knowledge from the individual to collective construction. They argue that education needs to be refashioned in a fundamental way so that students are initiated into a knowledge creating culture and see themselves as part of a global effort to advance knowledge.' According to McLoughlin et.al, [5] Web technologies can play a crucial role in fostering knowledge building in communities or networks and aid in the pre-eminence of content creation over content consumption and the collaborative production of knowledge. Grant [6] is of the opinion that these occur through a shared goal of developing and sharing ideas publicly with peers, offering critiques and alternative explanations. If our task is to transform educational practices, we have to provide some new ideas about how students' active engagement, meaningful learning and knowledge advancement could be facilitated.

\section{Background of the Study}

Constructivism holds that learners learn actively and construct new knowledge based on their prior knowledge. Prior knowledge is defined by Portier et.al [7] as being "dynamic in nature; available before a certain learning task; structured; explicit and tacit in nature; levels of conceptual and metacognitive components" Choo [8] states that "Knowledge creation is achieved through recognition of the synergistic relationship between tacit and explicit knowledge in the organization, and through the design of social 
processes that create new knowledge by converting tacit knowledge into explicit knowledge" To understand the true nature of knowledge, it is necessary to recognize that tacit and explicit knowledge are essential to knowledge creation [8]. In knowledge management, there are two kinds of knowledge: explicit and tacit[10-11].

Tacit knowledge is hard to articulate with formal language. Before tacit knowledge can be communicated, it must be converted into words, models or numbers that can be understood, whereas, explicit knowledge can be articulated into formal language. i.e., it can be expressed in words and numbers. Moreover, this kind of knowledge can be distributed as data, scientific formulas, reports, manuals, basic principles, and so on [11]. Explicit knowledge is easy to manage on a computer, communicate via the internet, and store in a database. In short, explicit knowledge refers to the "knowing about" (the objective knowledge), while tacit knowledge involves the "knowing how" (the subjective knowledge) [12].

Knowledge can be created through conversion between tacit and explicit knowledge by four different modes [8,10,13-14]. The four modes of knowledge conversion are created when tacit and explicit knowledge interacts with each other. These four modes are referred to as socialization, externalization, combination, and internalization. Nonaka and Takeuchi[10] represent the four modes in the form of a knowledge spiral.

\section{Tacit knowledge To Explicit knowledge}

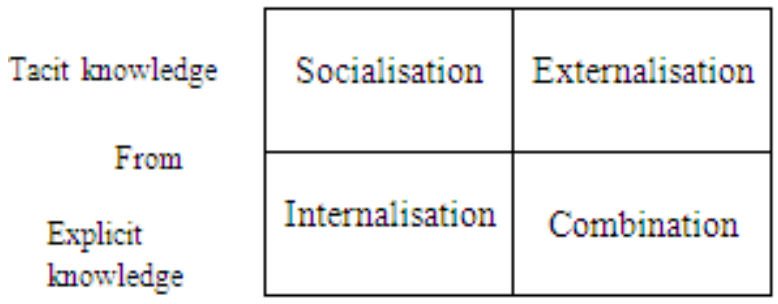

Figure 1. Four modes of knowledge creation [10]

1. Socialization involves social conversion to share experience from tacit knowledge to tacit knowledge. This process attempts to share experience and thereby to create and exchange tacit knowledge. Thus, socialization is used in sharing learners' experience and know-how with other learners.

2. Externalization involves the conversion of tacit knowledge into explicit knowledge. This process attempts to rationalize tacit knowledge and articulate it into explicit concepts and formal models (e.g., to write instruction manuals).

3. Combination converts explicit knowledge into more complex and systematic sets of explicit knowledge. This process involves individuals combining and exchanging different explicit knowledge to explicit knowledge with others. Existing learning information in the databases might be integrated to create new knowledge.
4. Internalization is a process of embodying explicit knowledge into tacit knowledge and internalizing the individual experiences gained through the other models of knowledge creation in the form of shared mental models. Through internalization, explicit knowledge created is shared through an online learning community and converted into tacit knowledge by individuals.

\section{Need and Significance of the Study}

The use of web technologies for the delivery of instruction continues to grow at an exponential rate. As an increasingly powerful interactive and dynamic medium for delivering information, e learning has many applications in the field of education. The use of e learning as an educational tool has provided learners and educators with a wider range of new and interesting learning experiences and teaching environments, not possible in the traditional class room. E learning environments create constructivist learning environment in our classrooms.

The secondary classes are complex social environments in which students talk to each other, write, learn and interact with one another. While meeting their social needs, they observe the physical and social world they interact scientifically, making guesses and explanations, question, make plans, hypothesize communicate and make comments. Further, they are also able to codify and document their findings in the form of reports. These processes are involved in the very act of knowledge creation. E- learning and web based environments extensively help accessing unlimited resources, communicating with a wide range of people, sharing knowledge, developing materials for collaborative work and documentation. E-learning aids in codifying and disseminating knowledge. That is, converting tacit to explicit and wise versa. Sorenson [15] is of the opinion that online technology is a mediator of codified representations and promotes the view that knowledge can be managed by codification.

So this study aims to find the effectiveness of e learning in improving knowledge creation ability in students.

\section{Objective of the Study}

To study the effectiveness of e learning in enhancing knowledge creation process in secondary class rooms.

\section{Hypothesis of the Study}

There is significant difference between the control group and the experimental group regarding students' knowledge creation ability.

\section{Methodology}

The post test only equivalent groups design given in Best 
[16] was employed for the study. Equivalence of the groups was ensured by randomly assigning subjects to experimental and control treatments.

\section{Sample}

The sample consisted of 80 secondary school students of standard IX.

\section{Procedure}

The experimental group was taught through e learning material prepared b by the investigators, based on a topic selected from their Physics text prescribed for study. The material included interactive animations, videos and links for searching the web. The control group is taught the same topic using the conventional method. Activities like project, seminars and problem solving are given to both the groups as part of the learning process.

\section{Data collection Tools}

In order to understand how the two groups perform according to the four modes of knowledge creation, they were given a subject for seminar presentation related to the learning topic. Rubrics were prepared and subjected to expert validation to measure student behaviour in four different modes of knowledge creation namely, socialization, externalization, combination and internalization, during the activity. Attributes were decided for performance in each mode and scored on a four point continuum ranging from excellent to poor performance.

\section{Data Analysis}

The scores of experimental and control groups for each mode was then compared using statistical techniques to find out whether the experimental treatment is significantly different from conventional method of teaching in enhancing knowledge creation ability in secondary school students. The statistical techniques used are mean, standard deviation and test of significance of difference between means.

\section{Analysis and interpretation of data}

The values obtained through the statistical analysis of data are given in the table below (Table 1).

From the t-values obtained, it is clear that the experimental group differs significantly from the control group in terms of the four modes of knowledge creation, namely, socialization, externalization, combination and internalization.

\section{Major Findings of the Study}

- The experimental group differs significantly from the control group, in the mode socialization of the process of knowledge creation.

- There is significant difference between the experimental and control groups regarding the mode externalization of knowledge creation.

- The experimental group differs significantly from the control group, in the mode combination of the process of knowledge creation.

- There is significant difference between the experimental and control groups regarding the mode internalization of knowledge creation.

The findings of the study is substantiated by studies conducted by Hakkarainen [17], where a series of studies at the elementary level education so as to facilitate progressive inquiry and practices of knowledge creation was conducted on Grade 5/6 students working within a computer supported classroom pursuing biological (Human Biology) and physical (Force, Electricity, Cosmology) study projects. A qualitative analysis of the epistemology of the students' inquiry culture indicated that knowledge produced by the class in question was at a very high explanatory level in both biology and physics. Moreover, Bereiter et.al [18-19] talked about schools as knowledge building communities in which both teachers and students work to build new knowledge and understanding.

Table 1. $\mathrm{t}$ - test for the post test scores of experimental and control groups for the different modes of knowledge creation

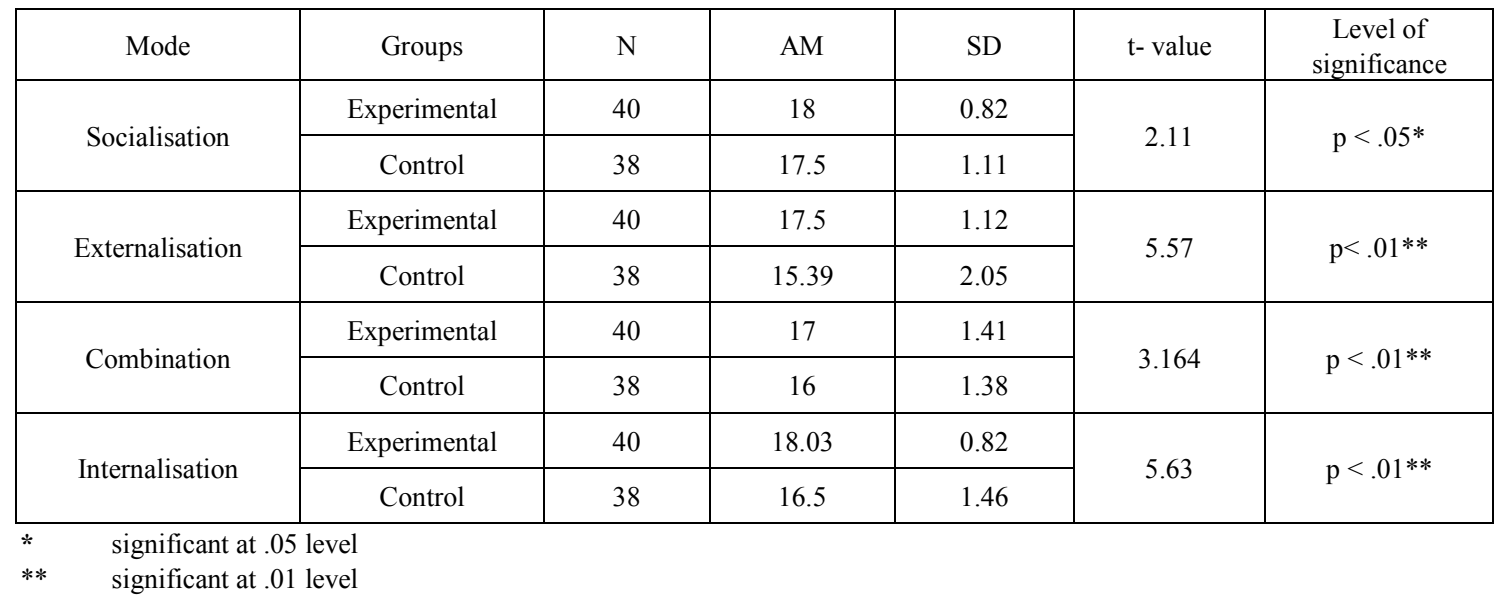




\section{Educational Implications}

- E-learning environments provide rich variety of experiences which help in enhancing the creativity and thereby aids in knowledge creation process.

- $\quad$ Teachers should try to develop a knowledge creating culture giving opportunities to share ideas and search for new knowledge.

- The process of inquiry aids the knowledge creation process.

- Project, seminars etc. are activities that encourage collaborative work. Collaborative work helps in knowledge creation.

- Knowledge creation is discussed above with either explicit or implicit position on how the knowledge is created. The appropriate use of online technology helps learners gain idea of tools for learning that they can use to develop the ability of knowledge management.

- Educators need to become skilled at converting personal, tacit knowledge into explicit knowledge through which they can help learners to construct their own knowledge.

- Multimedia technologies can make a great contribution to the educators' ability to transfer and share valuable knowledge to learners.

- Hypermedia environments, like visual, auditory, hyperlinks and video, allow the rapid dissemination of knowledge, thus making tacit knowledge explicit. As a result, courses which make use of videos, audio and animations which are Web technologies facilitate instructors to store their tacit knowledge externally.

- Multimedia course materials and instructions make it visible for learners and greatly contribute to individual development and management of core competencies.

\section{Conclusions}

To understand the true nature of knowledge, it is necessary to recognize that tacit and explicit knowledge are essential to knowledge creation. Knowledge can be created through conversion between tacit and explicit knowledge by four different modes. It is in this very act of conversion from tacit to explicit knowledge that learning is created. Educators must understand the dynamic nature of knowledge itself in order to practice effective knowledge management in multi-disciplinary contexts. It is also crucial for educators to focus on effective methods of delivering content, the media used, and the overall quality of the instruction materials. Then only it will become possible to refashion education in a fundamental way so as to direct students to a knowledge creating culture, which is the need of the hour. It is clear from the study that the appropriate use of online technology helps learners to develop the ability of knowledge management. Educators need to become skilled at converting personal, tacit knowledge into explicit knowledge that can help learners to construct their own knowledge. Multimedia technologies can make a great contribution to the educators' ability to transfer and share valuable knowledge to learners.

\section{REFERENCES}

[1] Vygotsky LS. Mind in Society: The Development of Higher Psychological Processes. Cambridge. MA: Harvard University Press; 1978.

[2] Lave J, Wenger E. Situated learning. Cambridge. UK: Cambridge University Press; 1991.

[3] Choy $\mathrm{SO}, \mathrm{Ng} \mathrm{KC}$. Implementing wiki software for supplementing online learning. Australasian Journal of Educational Technology. 2007; 23(2): 209-226.

[4] Scardamalia M, Bereiter C. Knowledge building: Theory, pedagogy, and technology. In: Sawyer K, editor. Cambridge handbook of the learning sciences. Cambridge. UK: Cambridge University Press. 2006; p. 97-118.

[5] McLoughlin C, Lee MJW. Listen and learn: A systematic review of the evidence that podcasting supports learning in higher education. In: Montgomerie C, Seale J. editors. Proceedings of World Conference on Educational Multimedia, Hypermedia and Telecommunications; 2007; p. 1669-1677). Chesapeake, VA: AACE

[6] Grant L. Using wikis in schools: A case study [internet]. c2006 [cited 2014 Oct 28]. Available from http://www.futurelab.org.uk/research/discuss/05discuss01.ht $\mathrm{ml}$

[7] Portier SJ, Wagemas LJJM. The assessment of prior knowledge profiles: A support for independent learning? Distance Education. 1995; 16(1): 65-87.

[8] Choo CW. The knowing organization: How organizations use information to construct meaning, create knowledge and make decisions. International Journal of Information management. 1996; 16(5):329-340.

[9] Nonaka I, Toyama R, Konno N. SECI, ba and leadership: A unified model of dynamic knowledge creation. Long Range Planning. 2000; 33:5-34.

[10] Nonaka I, Takeuchi H. The knowledge-creating company. New York: Oxford University Press;1995.

[11] Trentin G. From formal Training to Communities of practice via network-based learning. Educational Technology. 2001;16(5):5-14.

[12] Bolisani E, Scarso E. Information technology management: a knowledge-based perspective. Technovation. 1999; 19: 209-217.

[13] Choi B, Lee H. Knowledge management strategy and its link to knowledge creation process. Expert System with Applications. 2002; 23: 173-187.

[14] Malhotra Y. Knowledge management and new organization forms: a framework for business model innovation. Information Resources Management Journal.2000; 13(1):5-10.

[15] Sorensen C, Lundh-Snis U. Innovation through knowledge codification. Journal of Information Technology. 2001; 16: 83-97. 
[16] Best JW, Kahn JV. Research in Education. New Delhi: Prentice Hall of India Private Ltd.; 2005.

[17] Hakkarainen K. Progressive Inquiry in Computer supported Biology Classroom. Journal of Research in Science Teaching.2003; 40(10): 10721088.
[18] Bereiter C, Scardamalia M. Surpassing Ourselves. Open Court: Chicago; 1993.

[19] Bereiter C. Education and Mind in the Knowledge Age. Hillsdale, NJ: Erlbaum; 2002. 